\title{
¿Habrá de llamar una madre criminales a sus hijos? La conspiración del 23 de julio de 1833 contra el gobierno de Francisco de Paula Santander ${ }^{1}$
}

\author{
Patricia Cardona Z. ${ }^{2}$ \\ Universidad EAFIT (Colombia)
}

\section{Presentación del documento.}

\section{La conspiración del 23 de julio de 1833}

En medio del caos que había dejado la disolución de la República de Colombia (1819-1831) y de la división facciosa provocada por el recuerdo de Simón Bolívar (1783-1830), el presidente Francisco de Paula Santander (1792-1840) intentaba levantar, desde las ruinas, una nueva república: la Nueva Granada, en la que se mantenían activos los conflictos que habían derrumbado a Colombia, el gran país soñado por Bolívar. La pugna entre militares y políticos, la oposición de los artesanos y la Iglesia y la frágil situación económica, efecto de la deuda dejada por la extinta Colombia, habían producido un ambiente general de inestabilidad y fragmentación social. Santander y Bolívar aglutinan posiciones ideológicas antagónicas sobre temas relevantes en la época, tales como: las relaciones entre la Iglesia y el Estado, el libre cambio y el proteccionismo, la incorporación del sensualismo y el utilitarismo a través de los textos de Jeremy Bentham y Destutt de Tracy en detrimento de la escolástica, que había marcado los planes de estudio durante el dominio español. Esta candente situación favoreció la hostilidad política generalizada, que se expresó

\footnotetext{
${ }^{1}$ Texto derivado de la investigación Lenguajes y estrategias de paz, Colombia siglo XIX, con el apoyo de la Vicerrectoría de descubrimiento y creación de la misma universidad y radicado con el número 881.000001 .

2(azuluga@eafit.edu.co) Profesora investigadora del Departamento de Humanidades y miembro del grupo de Investigación en Filosofía, Hermenéutica y Narrativas de la Universidad EAFIT Medellín, Colombia.

ORCID 0000-0002-0182-5595.
} 
en rumores constantes de revueltas y en conjuras que ampliaban la brecha entre legistas y militares, santanderistas y bolivarianos, artesanos y comerciantes, políticos y clérigos, Iglesia y Estado.

En este clima de animadversión generalizada, empezó a planearse, desde finales de 1831, la conspiración descubierta el 23 de julio de 1833 , de la que secretamente participaba un grupo de seguidores de Bolívar, quienes se sentían traicionados por el presidente Santander y sus más próximos colaboradores en el gobierno. Un delator informó al presidente de los planes de sedición, en los que estaban involucrados 47 hombres, miembros, en su mayoría, de sectores populares. Esa acusación desencadenó una borrasca política en Bogotá con desastrosos resultados y cuyos efectos se sintieron durante el resto de la década, e incluso fue un argumento usado para favorecer o rechazar la promulgación de indultos durante la guerra de los Supremos (1839-1842).

La conspiración se había fraguado durante 18 meses, en los que, reunidos secretamente, los conjurados desplegaron diversas actividades: almacenaron armas y municiones, mantuvieron reuniones para ganar adeptos entre los clérigos, los funcionarios públicos, los artesanos y quienes habían visto burlados sus sueños con la República. Según narran las crónicas de la época, los promotores fueron tres connotados militares, dos de ellos -Mariano París Ricaurte (1788-1833) y José María de la Serna y Ricaurte (178?-1835)- emparentados entre sí y miembros de una importante familia bogotana; y el navarro José Sardá (1882-1834), exmilitar que había combatido en España, Francia, Rusia, México; llegó a Colombia hacia finales de 1820 y se convirtió en mando militar de la provincia de Riohacha ${ }^{3}$, en la frontera entre Colombia y Venezuela. Sardá tuvo allí un papel destacado: controló las sediciones de las regiones adyacentes contra la República en ciernes y ayudó a instaurar el orden republicano después de conseguida la Independencia. Desafortunadamente, el navarro se granjeó la enemistad de varios jefes militares que veían en peligro su posición a causa de su destacada labor; debido a ello, y tras haber sido ascendido a general, el 3 de diciembre de 1831 Sardá fue degradado y borrado de la lista militar, quedando en una calamitosa situación social y económica y humillado como oficial del ejército de la República de Colombia ${ }^{4}$. Además de París, De la Serna y Sardá, la conspiración contó con el apoyo y la participación de un grupo de militares de rango medio y bajo del regimiento Húsares, adeptos a Bolívar y contrariados por el tratamiento indigno que, en su concepto, les daba el gobierno santanderista, responsable de haber tergiversado los ideales bolivarianos y torcido el rumbo de la república.

\footnotetext{
${ }^{3}$ Biblioteca Nacional de Colombia (BNC), Fondo Pineda 361, pieza 3. Defensa del Ex-Jeneral José Sardá en la causa de la conspiración del 23 de julio de 1833 proclamada en los estrados del Tribunal de Apelaciones de este distrito por su defensor Doctor Eladio Urisarri, Bogotá, impresa por Andrés Roderick, 1833, p. 11.

4 Joaquín Posada Gutiérrez, Memorias histórico politicas, Medellín, Editorial Bedout, Tomo II, p. 441.
}

Araucaria. Revista Iberoamericana de Filosofía, Política, Humanidades y Relaciones Internacionales, año $22, \mathrm{n}^{\circ} 44$. Segundo semestre de 2020. Pp. 623-634. ISSN 1575-6823 e-ISSN 2340-2199 https://dx.doi.org/10.12795/araucaria.2020.i44.32 


\section{En contra de la conspiración y en defensa de la República}

La conspiración aglutinaba a los detractores de Santander, sus miembros se presentaban como defensores del legado de Bolívar, de la protección comercial, de los artesanos, del clero y de la religión. Por su parte, los círculos liberales, congregados en torno al gobierno de Santander, se referían a aquella conjura como la acción de un grupo de resentidos y retardatarios simpatizantes de la colonia y la tiranía, y dispuestos a "restablecer las leyes españolas y el gobierno de los años ocho i nueve".

Los sediciosos fueron tratados sin miramientos; menos de un mes antes de que se descubriera la conjura, el 3 de junio de 1833, se había expedido la Ley sobre el modo de proceder en las causas sobre sedición y conspiración, en cuyo artículo 23 se imponía la pena de muerte para quienes "aconsejen o fermenten la rebelión, traición o conspiración" contra las autoridades constitucionalmente establecidas $^{6}$. La ley en cuestión, como lo indica su título, esclarecía el delito político, los procederes, los tiempos procesales y las instancias que debían garantizarse para la judicialización de los reos, indicadores de la implementación de la justicia penal moderna ${ }^{7}$.

La conspiración que, como dijimos antes, había tomado 18 meses de preparación, expresaba la inconformidad y "descontento de frailes y clérigos y borrados de la lista militar",; en total fueron capturados y sentenciados 47 involucrados. Junto a los protagonistas mencionados antes, participaron también varios militares de bajo y mediano rango, de quienes no quedan datos precisos, salvo los nombres ${ }^{9}$ y la información registrada en los documentos de juicio y sentencia sobre la participación de cada uno de ellos en el complot ${ }^{10}$.

${ }^{5}$ BNC Fondo pineda 361, pieza 2, Ultima vista fiscal, sentencia y otros documentos importantes relativos a la causa seguida a los cómplices en la conspiración descubierta en esta capital en la noche del 23 de julio de 1833. Publicados de orden del gobierno. En la imprenta de Nicomedes Lora, año de 1833 , p. 33.

${ }^{6}$ Ley sobre el modo de proceder en las causas sobre sedición y conspiración, En Gazeta de la Nueva Granada 1832- 1833, No 90, trimestre 6, Bogotá, 16 de junio de 1833, p. 107.

${ }^{7}$ Enrique Alberto Parada García, "Una historia del delito político: sedición, traición y rebelión en la justicia penal neogranadina (1832-1842)", en Anuario colombiano de historia social y de la cultura, vol. 39, no 2, pp. 101-130, 2012 http://www.scielo.org.co/pdf/achsc/v39n2/v39n2a05.pdf

${ }^{8}$ BNC, Fondo Pineda 361, pieza 3. Defensa del Ex-Jeneral José Sardá, p. 3.

${ }^{9} \mathrm{BNC}$, Fondo pineda 361, pieza 2. Ultima vista fiscal sentencia y otros documentos, p. 1. El listado de involucrados en la conspiración formado por los siguientes nombres: José Sardá, Ignacio Amaya, Juan, Alejo, Pedro y Manuel Arjona, Ignacio, Mauricio y Juan Nepomuceno Acero, Francisco y Antonio Grillo, Francisco Amaya y Vicente Ramírez, Antonio Nieto, Manuel Izquierdo, José María Sandoval, Juan Amaya, Juan Nepomuceno Franco, Juan Nepomuceno Escandón, Matías Zuñiga, Estanislao, Telmo, José y Juan Santos, Lucas Gracia, Agustín y Valentín Yepes, Francisco Caimán, Juan y Nepomuceno Barrera, Francisco Caicedo, Isidoro Cárdenas, Salvador Pulido, Nicolás y Manuel Sánchez, Benedicto y José Antonio Prieto, Pioquinto López, Gregorio y Alejo Rodríguez, Pedro Zornoza, Juan Nepomuceno Molano, Victoriano y Antonio Jiménez, Francisco Rojas, Andrés Salgado, Cruz Zabala, José María Morales, Carlos Arenas, Antonio Díaz, José María Galindo, Pedro Benavidez, Luis Vanegas, Juan José Sanabria, Domingo Martínez, Fray Jose Salabarrieta y José María Barrionuevo.

${ }^{10}$ BNC, Fondo pineda 361, pieza 2. Ultima vista fiscal sentencia y otros documentos, p. 3. 
Para evadir la pena de muerte, muchos implicados adujeron en su defensa que habían sido obligados por los líderes a participar de los planes de conjura. Pero los fiscales se mostraron inflexibles y, a fin de defender al gobierno y escarmentar a posibles confabulados, dieron a todos los implicados tratamiento criminal, con el argumento de que se trataba de sujetos acostumbrados a transgredir las leyes: "uno es homicida, el otro estuprador violento, aquél ladrón, este parricida, uno hijo malvado, aquel tramposo, muchos vagos y casi todos, en fin, revoltosos"11; en consecuencia, de haber sido exitoso el complot, decía el tribunal, "ninguno de nosotros existiría"; su mala conducta presagiaba el caos y la perdición de la República en manos de aquellos "carniceros" que, según los fiscales, estarían "insultando nuestros cadáveres"12. Con este lenguaje cargado de metáforas e imágenes se presentó la pena de muerte del grupo en pleno como el mejor medio de "expiar su delito en el patíbulo"13.

\section{Una familia de sediciosos}

Del grupo de los 47 sediciosos hacían parte cuatro miembros de la familia Arjona Lizarralde, "conocidamente desafecta al gobierno"14: Pedro, Manuel, Juan y Alejo participaron activamente en los planes conspirativos; uno de ellos, Pedro, asesinó al teniente José Manuel Montoya, a quien, al ser develado el complot, se le encomendó su captura; siendo este la única víctima directa de estos eventos. Esta muerte agravó la situación de los implicados y, sin duda, incidió en la condena a muerte que se decretó de manera generalizada en la primera sentencia.

A pesar de que Pedro había sido borrado de la lista militar, su familia gozaba de privilegios de la República, "algunos de sus hermanos estaban colocados en empleos y otros en goce de retiro con pensiones que aseguraban su subsistencia"15. Con ese argumento los detractores de los Arjona justificaban la acusación y la pena a muerte. Al tiempo, los enemigos de la mencionada familia difundían, a través de impresos populares como hojas sueltas y pasquines, información que los presentaba como parentela de facciosos, enemigos de un gobierno que los había colmado de beneficios, a quienes antes que la legitimidad, el orden o la regeneración de la república, les movía "el deseo de manejar a gusto las arcas del gobierno"16.

${ }^{11}$ BNC, Fondo pineda 361, pieza 2. Ultima vista fiscal, sentencia y otros documentos, p. 33.

12 Ídem.

13 Ídem.

14 BNC Fondo Pineda 469, pieza 49. A los extranjeros y ciudadanos granadinos imparciales que nos observan, Bogotá, Imprenta de Nicomedes Lora, 1833, hoja suelta.

15 BNC Fondo pineda 361, pieza 2. Ultima vista fiscal, sentencia y otros documentos, p. 7.

16 BNC Fondo Pineda 469, pieza 49. A los extranjeros y ciudadanos granadinos, hoja suelta, 1833. 
Este intento sedicioso evidenció las brechas sociales entre "gente de levita y zapatos y gente descalza" ${ }^{17}$, que mantenía a las élites letradas en actitud defensiva contra las posibles revueltas del pueblo mestizo y pobre. Las nacientes facciones políticas, germen de los partidos Liberal y Conservador que se definieron después de 1842, supieron hacer uso de un lenguaje político "refigurado", en términos de Paul Ricoeur ${ }^{18}$, a través de las creencias religiosas y de imágenes emotivas que penetraban ideológicamente en las clases populares, que por lo general accedían a los discursos políticos a través de mediadores culturales, tales como lectores públicos, oradores, maestros y clérigos. De allí, por ejemplo, la reiteración entre los partidarios del gobierno, detractores de la influencia Bolivariana, de que aquellos conspiradores buscaban "el restablecimiento de los honores de Bolívar (cuya sombra turba todavía la tranquilidad del país)" ${ }^{\prime \prime}$, mientras que los opositores de Santander acusaban de "ingratitud de los gobiernos republicanos" ${ }^{20}$, incapaces de reconocer y retribuir a los militares y la Iglesia su participación en las guerras de Independencia y en la fundación de la República.

\section{Conmutación de la muerte por presidio}

El juicio y la sentencia de los conspiradores exacerbaron los antagonismos entre diversos sectores de la sociedad. Por un lado, estaban los fiscales, distinguidos liberales cercanos al presidente Santander, quienes tenían el deber de aplicar las penas correspondientes según la ley de sedición, las cuales debían servir de escarmiento y asegurar que "no se volteará el sistema ni las instituciones por los esfuerzos de los enemigos de la patria"21. Por otro lado, estaban los que calificaban la pena de muerte como un castigo excesivo y contrario a los predicamentos liberales de los seguidores de Santander, que en ocasiones anteriores se habían opuesto a su aplicación. El debate que produjo la sentencia contribuyó seguramente a que el gobierno conmutara la pena de muerte por el presidio en fortalezas conocidas por sus duras condiciones locativas y por la rudeza e insalubridad del clima: las prisiones Chagres y Cartagena eran temidas por el calor, el hacinamiento y los malos tratos a los que se sometía a los presidiarios. Entre los "beneficiados" por la conmutación estaban dos jóvenes que, al parecer, no habían llegado a los 18 años: Manuel Anguiano y Alejo Arjona, miembro este último de la ya mencionada familia

\footnotetext{
${ }^{17}$ Angel y Rufino José Cuervo, Vida de Rufino Cuervo y noticias de su época, Paris, A, Roger y F. Chernoviz, libreros y editores, 1892, p. 177.

18 Paul Ricoeur, Tiempo y narración 3. El tiempo narrado, México, Siglo XXI, pp. 864-928.

19 BNC, Fondo pineda 361, pieza 2. Ultima vista fiscal, sentencia y otros documentos, p. 3.

${ }^{20}$ BNC, Fondo Pineda 361, pieza 3. Defensa del Ex general José Sardá, p. 10.

${ }^{21}$ BNC, Fondo Pineda 469, fol. 710. Para los granadinos i no granadinos, Bogotá, Imprenta de Nicomedes Lora, s.f., hoja suelta.
}

Araucaria. Revista Iberoamericana de Filosofia, Política, Humanidades y Relaciones Internacionales, año $22, \mathrm{n}^{\circ} 44$. Segundo semestre de 2020. Pp. 623-634. ISSN 1575-6823 e-ISSN 2340-2199 https://dx.doi.org/10.12795/araucaria.2020.i44.32 
Arjona. Manuel Anguiano era hijo adoptivo de José Sardá; en medio del torbellino político, Anguiano pudo huir por unos meses, pero capturado en Casanare y conducido a Bogotá fue fusilado unos meses después, el 18 de diciembre de 1833 .

Alejo Arjona era el menor de los miembros de la familia Arjona involucrado en la conspiración; siendo

uno de los más comprometidos en ella", su corta edad no conmovió a los fiscales, quienes omitieron los testimonios de la defensa en los que se aseguraba que el joven "no piensa sino en cosas santas, que no es capaz de tener opinión (...) que marchó con la fascinación porque marchaban también sus hermanos ${ }^{22}$.

El joven recibió la condena a muerte, pero seguramente su corta edad jugó a su favor en la conmutación de la pena de muerte por la de presidio en Chagres.

La dramática situación de la familia Arjona, con cuatro de sus miembros directamente involucrados en la conspiración, sentenciados muerte y sin posibilidad de obtener clemencia alguna por parte del presidente Santander, llevó a Juan, uno los hermanos involucrados en la insubordinación, a proponer un trato al gobierno: relatar de manera "franca y sencilla de cuanto existe en virtud de la conspiración", a cambio de que en caso de sentenciarse contra él y su hermano Alejo la pena capital, ésta fuera conmutada "por destierro a donde a bien tenga el gobierno"; pedía, eso sí, que este ofrecimiento fuera manejado con reserva, pues en virtud de su formación militar preferiría "morir mil veces que convenir en ser mirado como un vil denunciante"23. El gobierno rechazó el ofrecimiento de Juan Arjona debido a que, según el presidente Santander y su secretario Lino de Pombo, carecía de competencia para negociar con un criminal insurrecto y, además, debía evitarse que, con el propósito de ser indultado, un reo pudiera involucrar a personas inocentes con falsos testimonios. Así, el gobierno decidió echar "un denso velo sobre el origen y efectos de las presentes calamidades" promovió el olvido a los males dejados por la conspiración y renunció a continuar con investigaciones y pesquisas para encontrar más conspiradores.

Finalmente, el gobierno expidió el Decreto del 13 de octubre de 1833 "conmutando la pena capital a 28 de los reos". Un grupo formado por 19 inculpados recibió, a cambio de la pena de muerte, diez años de presidio en la fortaleza de Chagres; los nueve penados restantes fueron enviados a las cárceles de Cartagena de Indias por 8 años ${ }^{25}$. Los veintiocho reos restantes

${ }^{22}$ BNC, Fondo pineda 361, pieza 2. Ultima vista fiscal, sentencia y otros documentos, p. 9.

23 "Documento sobre la repulsa que hizo el gobierno del ofrecimiento de no de los reos de hacer denuncia", En Gazeta de la Nueva Granada, No 108, trimestre 8, Bogotá, domingo 20 de octubre de 1833 , p.194.

24 "Documento sobre la repulsa que hizo el gobierno del ofrecimiento", p.194.

25 "Decreto del gobierno conmutando la pena capital a 28 de los reos condenados a ellos, en la causa de conspiración y sentencia del tribunal de apelación del Departamento de Cundinamarca, en 
fueron fusilados el 16 de octubre de 1833, "con todo el horrible y lúgubre aparato" 26 desplegado tradicionalmente para las ejecuciones. El exgeneral Sardá logró huir el 11 de octubre, días antes de su ejecución; oculto en la casa de un clérigo amigo suyo, mantuvo su actividad conspiratoria durante casi un año más. Engañado por dos jóvenes que se hicieron pasar como simpatizantes del complot, fue asesinado por ellos en 1834.

\section{Una madre que pide clemencia}

Cuatro años después de estos sucesos vuelve a tenerse noticia de la familia Arjona; esta vez es la madre Josefa Antonia Lizarralde, quien haciendo uso del derecho a expresarse públicamente envía una carta a las autoridades respectivas para solicitarles clemencia para su hijo Alejo, que se hallaba pagando su condena en el presidio de Chagres. Después de la conspiración de 1833, la señora Juana Josefa quedó al frente de una familia numerosa; Pedro, su marido, y su hijo Manuel, fugitivos, su hijo Juan ejecutado y el menor Alejo, preso; su situación era desesperada: a la necesidad de brindar el sustento a una familia numerosa, sin el apoyo de un hombre que la ayudara a soportar la carga económica y social, se sumaban las noticias de la pésima situación de Alejo en el presidio y los castigos a los que se le había sometido, hechos que, seguramente, le dieron el valor necesario para dirigir una carta a las autoridades solicitando una actitud benevolente hacia su hijo. Es la carta que transcribimos aquí, una pieza de interés por varias razones, entre ellas: se trata de una mujer que toma la pluma (o lo hace a través de un intermediario de la escritura) para llamar la atención de las autoridades sobre la mala situación de su familia; pero es también una mujer que, aunque invoca la clemencia, esgrime razones jurídicas y políticas en la solicitud del indulto para su hijo. La epístola empieza por declarar la situación precaria que sufren ella y sus hijos, el abandono y la falta de un hombre que le ayude a solventar las penurias; luego refiere el trato infame y las malas condiciones en las que vive su hijo preso; finalmente, la carta adquiere un tono más razonado para señalar las facultades del gobierno para conceder indultos y amnistías. En esta carta hay información interesante sobre la vida en los presidios y la sanción política a la que eran sometidos los familiares de los reos políticos; es un documento en el que una mujer eleva su voz para reclamar un trato más benigno para con sus seres queridos; sin embargo, el gobierno no dio su brazo a torcer, todos los condenados en Chagres murieron, porque allí, "solo por milagro se puede vivir (...) mejor les hubiera sido a aquellos infelices que los hubieran fusilado"27.

Gazeta de la Nueva Granada, No 108, trimestre $8^{\circ}$, domingo 20 de octubre de 1833, p. 193.

${ }^{26}$ Ángel y Rufino José Cuervo, Vida de Rufino Cuervo y noticias de su época, p. 177.

27 Joaquín Posada Gutiérrez, Memorias histórico politicas, p. 453. 
BNC, Fondo Pineda 466, pieza 113

\section{Documento}

\section{Carta de Josefa Antonia Lizarralde de Arjona, pidiendo al gobierno clemencia por su hijo Alejo Arjona, preso en Chagres.}

Honorables Senadores y Representantes.

La providencia sabia en sus consejos con su omnipotente diestra trazó las instituciones granadinas que los escogidos de este heroico pueblo sancionaron para su dicha y bienestar: obra digna del cuerpo del sendero trazado a otros mortales más felices, persuade lo elevado de su origen. Ejerced aquella virtud divina, salvada, sí, redimid aun uno de vuestros conciudadanos que experimentan prolongadamente tormentos crueles, privaciones y toda clase de sufrimientos, y seréis colmados de mil eternas bendiciones.

Con el más doliente acento y anudadas voces, os habla hoy por tercera vez anegada en copioso llanto desde su triste lecho donde la ha postrado el dolor y amargura de sus penas, la contristada, abatida y decadente madre de los Arjonas infelices; ¿me escuchareis? sí, no lo dudo.

¿Para que pretender el imposible de bosquejaros en lastimero y conmoviente cuadro de inauditos infortunios que han aquejado a esta familia mil veces desgraciada? Empero, no obstante, figuraos Señores una numerosa descendencia que poseía considerables intereses y fueron abandonados y perdidos por haberse consagrado sucesivamente todos sus miembros al servicio de su patria, y de improviso se hallaron sin destino ni producto alguno quedando así reducidos a la indigencia; que en tan aflictiva situación sobreviene el funesto 23 de julio de 1833, y un querido hijo es arrojado hasta el patíbulo, otro arrastra la ominosa y cruel cadena de un presidio, otro expatriado de sus suelo y de sus hijos miserables, su infelice y anciano padre y casi el resto de varones fugitivos, y yo destituida de salud, de fuerzas, de apoyo alguno, rodeada de cuatro vírgenes y dos varoncitos que inocentes padecen las horrorosas consecuencias de tan espantosa situación. Empero, ¿a dónde voy? distraería demasiado vuestra atención si pretendiese compendiar la multitud, enormidad y prolongación de los padecimientos de mi atormentada familia i¿Habrá de llamar una madre amorosa criminales a sus hijos?; $\ldots$

La virtud más preciosa y recomendable del hombre en sociedad es la beneficencia con sus semejantes, vosotros la poseéis, y en vuestras manos, sí, en vuestras manos, ha depositado el libro santo de las instituciones del estado al remedio de tantos males: aplicadlo a estos desafortunados granadinos: un 
indulto tantas veces suspirado pondrá término a semejantes calamidades, y el artículo 74 atribución $16^{\mathrm{a}}$ de aquel libro os da la facultad: ¡os negareis a proteger al desgraciado? no ciertamente.

Quisiera, Señores, terminar aquí esta reverente impetración; no obstante disculpadme y permitid que ocupe un momento más vuestra atención.

Contemplado entre los fugitivos de mi lastimada familia a mi esposo agobiado bajo el enorme peso de la ancianidad, de enfermedades graves, de privaciones tal vez las más exigentes en la vida y ulcerado con mil agudos tormentos tanto morales como físicos, siendo empero el apoyo y consuelo de una prole dilatada.

La preciosa y dulce prerrogativa de "conceder indultos generales cuando lo exija un grave motivo de conveniencia pública" es amplia y sin la menor restricción; está, pues, dentro de la esfera de vuestros poderes no excepcionar individuo alguno de los que padecen por causas políticas. El sentido literal y aun el mismo espíritu de la constitución están de acuerdo en este punto, pues que ella no ha definido cuales deban entenderse por indultos generales, y si se duda acaso, a vosotros pertenece decidirlo (artículo 213 de la constitución) conforme al sentido natural de las voces, a lo que persuade la razón, y sugiere la humanidad; ¿sería general un indulto circunscrito únicamente a los prófugos? Todo aquello que no es común a las cosas de una misma especie, nunca puede llamarse general, y si aquel indulto se contrae a ciertos individuos determinadamente, si no abraza las diferentes especies y grados de los delitos político que hayan tenido lugar en el período comprendido en él, la gracia sería propiamente dicho especial o particular, y no general de cuya voz usa la constitución, sin especificar si solo a los procesados, o si también a los ya rematados haya de extenderse. No haciéndose, pues, tal limitación la facultad será extensiva a todos indistintamente, porque la ley no permite restricciones que ella no ha establecido; porque en todo caso una prerrogativa tan benéfica y humana que en multitud de circunstancias puede producir los efectos más ventajosos y saludables al estado, debe siempre entenderse en el sentido más extenso; y porque contraída ésta facultad a los casos que haya motivo de conveniencia pública, no hay peligro en que se abuse de ella; y aquél motivo comprende también a los sentenciados y rematados.

El que posee la facultad de minorar o rebajar la pena impuesta por una sentencia ejecutoriada, la tiene también para perdonarla del todo, y nadie ha dudado que en vosotros reside la primera facultad, pues que en el código penal que acaba de acordarse uno de sus títulos se encuentran determinaciones sobre rebaja de la pena a los que están sufriendo condenas. Aún hay más ¿habrá despedazado el Congreso la constitución vigente en alguno de sus actos?; pues bien, registrad Señores el decreto legislativo sancionada en 28 de mayo del año que finó, y encontrareis a Cayetano Tavera indultado en él, de cierta 
cantidad que por sentencia ejecutoriada de los respectivos tribunales del orden judicial, fue condenado a satisfacer al tesoro de la nación. Así que, residiendo en los legisladores granadinos la facultad que nadie podrá negarles de conceder gracias tal como de la que hago mérito, con mayor razón le es dado otorgar una amnistía general para la que señaladamente le autoriza la carta constitucional, sin que por eso haya de invadirse el poder judicial, porque si así fuese jamás vendría a ofrecerse el caso de ejercer que la atribución laudable, puesto que desde el instante mismo en que cualesquiera ciudadano fue acusado de un delito y el respectivo tribunal inicia el juicio, entra el reo bajo la inmediata y exclusiva acción de aquel poder, y si en el seguimiento de la causa puede la legislatura cortar la acción de los tribunales de justicia, tanto puede hacer lo menos como es indultar al individuo no ya del todo de la pena impuesta sino de una parte de ella cuando terminaron como terminan las funciones judiciales desde el momento en que dictaron su sentencia, de manera que la invasión más bien se habría en privar o cortar el procedimiento del juez o tribunal, que condonando al individuo de la pena después de haber llenado aquél su facultad. Opónense también la razón y la justicia a la desigualdad que habría beneficiando a los que aún no han sufrido los tormentos de un juicio temeroso y parte de la pena impuesta; y segregando de la gracia a los que ya experimentaron su rigor. Agréganse a estas consideraciones la de que mi infeliz hijo Alejo es aún demasiado joven; pero el mayor de los célibes, y por lo mismo casi el único en que se fundaba la esperanza del alivio de la miseria de sus decadentes padres, y del crecido número de sus hermanas desvalidas, cuya orfandad consterna. Este débil joven ha sufrido ya el espacioso tiempo de cuatro mortales años en el mortífero presidio de Chagres agobiado con toda clase de escases y tormentos: pero ¡ah! sin duda el más cruel, arbitrario y bárbaro fue el que le hizo padecer el comandante de aquella fortaleza en 30 de agosto del año próximo pasado: después que le insulta y le da de bofetadas, hace formar la tropa y presidiarios le conduce violentamente, le desnuda y atándole a un cañón de la batería le hace dar en público ciento y cincuenta palos por cuatro soldados y un cabo los más robustos y esforzados, hasta que reventando sangre por todo aquel molido cuerpo cae en tierra exánime; mas no satisfecha la ferocidad de aquel brutal soldado por solo suponer en mi hijo la intención de fugarse del presidio, al día siguiente que se hallaba de nuevo en sus sentidos lo pone y conserva veinticuatro horas en capilla con todo lúgubre aparato de aproximarle su último momento; pena tremenda y tal vez mayor que la que está sufriendo en el presidio, empero no basta todavía para menguar la saña de su opresor tirano; ¡lo creéis!; escuchadme Señores que os hablo de verdad; se apura aún la copa amarga de tormentos: el mismo comandante con fecha de 12 del último Diciembre previene a las seis de la mañana al sobrestante que haga salir a Alejo a los trabajos, se le manifiesta lo que no ignoraba, que en aquel momento 
sufría el ataque de las más horrorosas calenturas que por quince días continuos lo tenían postrada en cama, y contesta con sultánica arrogancia, que salga sin embargo a los trabajos; manda pues, el sobrestante al cabo que lo saque, y éste vuelve anunciando hallarse el infelice en un estado lastimero e imposible de moverse aquel momento; que lo saquen no obstante, repite el comandante, y cumplida su orden resulta de ella tal trastorno en la paciente víctima, que apenas fue sacado cuando ofrecía el aspecto de un tronco inanimado. Conforme a las leyes vigentes, cuando se ejecuta en un reo cualesquiera castigo arbitrario en la prisión durante su juzgamiento no puede aplicársele la pena detallada por la ley, porque a nadie debe imponerse dos castigos a la vez; ¿y será posible que habiéndose practicado con mi hijo aquel escandaloso hecho que naturalmente lo ha inutilizado, y después de haber cumplido casi la mitad de su condena, no sea libertado de la parte que le falta?

Se dirá tal vez que el Congreso no puede hacer lo que no hacían los soberanos absolutos, empero hay mucha diferencia entre los indultos expedidos por aquello y los que están en poder de la legislatura el acordar. Los perdones de los soberanos de la Península se promulgaban para toda clase de delitos sin ningún motivo de conveniencia pública, y por diversidad de acontecimientos faustos que vosotros sabréis eran muy frecuentes, siendo forzoso por lo mismo comprender la gracia solo a aquellos que aún no estaban rematados o cuyas circunstancias agravantes en la comisión del crimen no anunciaba los últimos grados de la perversidad humana; porque de otra manera se hubiera relajado del todo los vínculos de la obediencia y del orden; sin embargo en los delitos políticos (para con aquellos reyes) han repetido ellos mismos los ejemplos de indultar algunos que ya habían sido rematados, y en esta capital existen los doctores Javier Cuevas, Joaquín Ortiz, y otros ciudadanos que acogiéndose a la gracia de 1817 y 1820, regresaron a sus hogares de los presidios en que arrastraban cadenas ponderosas. Además si como lo he dicho ya, los decretos reales de amnistía no tenían por lo común una amplitud total era porque no se relajasen la moral y demás vínculos sociales, pues que siempre se referían a toda clase de delitos, riesgo a que no están expuestos los que pueden ahora decretar los delegados de la Nación, porque ellos deben basarse en un motivo de conveniencia pública, que existe poderoso en el presente caso.

En una república naciente, nada es tan esencial para su consolidación como destruir todos los gérmenes de discordia y de odio entre los ciudadanos, necesidad más urgente e imperiosa, cuando han presidido largos intervalos de desavenencias y agitaciones civiles, y a tiempo que empieza un nuevo y sin duda brillante periodo constitucional.

$\mathrm{Si}$ al principio de un trastorno es indispensable alguna severidad para con los que en efecto se han extraviado a fin de traer a todos los ciudadanos a la obediencia, hacer respetar las leyes, y restablecer los deberes sociales, estos 
momentos terribles deber ser prontos y rápidos; conviene que desaparezca inmediatamente el espectáculo de los procesos judiciales y de los castigos, manantial y fomento de las animosidades y venganzas; solo debe conservarse de ellos de una manera saludable.

Es tiempo ya Señores de que cese toda investigación y procedimiento judicial respecto de los acontecimientos políticos de los años anteriores, sí, es tiempo ya de que los fugitivos pueda restituirse a sus casas y presentarse en público para atender a sus familias, a la reparación de sus fortunas y al cuidado de su subsistencia; es tiempo en fin de que mi desgraciado Alejo condenado a los duros trabajos y miserias del peor de los presidios, y el que está expulsado de su patria, vuelvan a pisar la tierra en que vieron la primera luz, a reconocer sus hogares y estrechar las prendas más queridas da todo ser humano.

El objeto ofrecido en la conmutación de la pena de último suplicio, nunca es otro que el de conservar la vida al agraciado para la sociedad, para él, y para sus deudos, y ¿podrá llenarse aquello continuando Alejo en Chagres clima el más insano y después del daño producido en él por la extraordinaria pena de los palos que sufrió?; morirá sin duda allí antes cumplir su tiempo, morirá de una manera paulatina, y entonces más valiera haber acabado de una vez sin la multiplicidad de semejantes penas; pero no que vivara menos infeliz al lado de sus padres, si , vivirá menos infeliz al lado de sus padres, si, vivirá por vuestra indulgencia y filantrópicas ideas.

Un acto tan grandioso acabará de reconciliar a los ciudadanos, los reunirá a todos entorno del gobierno, bajo la benéfica sombra de la Constitución, los acerca uno a otros, aniquilará los restos de las discordias pasadas, y con la unión de todos los miembros de la familia, granadina, producirá bienes positivos al país a los favorecidos y sus familias, y dando mayor fuerza y robustez al gobierno, pondrá el último sello a la consolidación de la Republica. He aquí Señores ¿qué motivo más grave de conveniencia pública puede nunca presentarse en apoyo del fin deseado?

Una amnistía tal cual la imploro a vosotros es altamente generosa y honorífica para el augusto cuerpo de los representantes del pueblo, y produciendo largos días de júbilo en una porción de infortunados granadinos, vuestros nombres serán pronunciados con una gratitud reverencial, atrayéndoos las más puras bendiciones del eterno, y de mil generaciones.

Bogotá, marzo de 1837. Señores

Josefa Antonia Lizarralde de Arjona 